\title{
THE HEALTH-RELATED MARKET IN CZECH REPUBLIC AND DENMARK: AN EXPLORATION OF CONSUMPTION EXPERIENCES
}

\section{Chytkova, Z., Brogård Kristensen, D.}

Due to the rise in consumers' "health-conciousness", the health-related market has become one with the most potential. However, most studies on health-related consumption have been carried out within the Western world, while the evolution of health management in Central and Eastern Europe has been radically different. This paper builds on two separate qualitative studies of consumers' perception and practices in the sphere of health and food in Denmark and the Czech Republic. Each of these studies explored in its own way, how consumers in each of the two cultural settings deal with consumption through different forms of governmentality. It shows how in the Danish setting the notion of agency and the reflexive self unfold as a theme where consumers depend on an inner voice and a "gut feeling", while in the Czech context consumers increasingly seek guidance from expert systems. These findings thus enlighten the meanings and processes behind consumer choices, having significant implications for marketing of companies operating on these growing markets.

Keywords: Marketing; consumer behavior; food; health; consumer culture.

JEL Classification: M3, D11

\section{Introduction}

Health-related expenditures are rising throughout the developed world. Most of the health-care cost is associated with non-communicable diseases, mostly cardiovascular and cancer. The underlying condition of their spreading, as well as of the increasing expense, has been called a "lifestyle epidemic." Transnational organizations such as World Health Organization or OECD, as well as national governments, are looking for ways to overcome this problem. A war against lifestyle epidemic has been declared on both international and national levels throughout the developed world, mostly based on the rational consumer model. This model is to a large degree associated with a "neoliberal perspective [that] insists on seeing all social actors [as ...] a flexible bundle of skills that reflexively manages oneself as though the self was a business" (Gershon, 2011). In other words, the individual consumer is seen as responsible for her/his own health. The insistence of the public discourse on the individual responsibility for one's health has resulted in the steep rise of health-related spending of individual consumers, resulting in a fast growing health-related market. This market is not limited to health care, but spans heterogeneous sub-markets such as self-education, exercise and especially food.

The growth of the health-related market is closely connected to the notion of the "choosing self" in the context of late modern consumer culture, in which a consumer's identity is not ascribed by social structures, but in which consumers are regarded as free (and obliged) to create their self as a reflexive project (Giddens, 1991) mainly through their consumption choices. The body is a central and visible part of the reflexive self. It is not a passive object, but an entity designed through bodily regimes, such as eating 
habits, exercise or health care (Giddens, 1991). According to Brian Schilling, consumers have an unprecedented degree of control over their bodies, but they also live in an age that has thrown into radical doubt what bodies are and how they should be controlled (Shilling, 2003, p. 3). In this setting it is the market that offers options for the creation of (healthy) bodies. These options, however, are not uniform. They vary widely depending on the characteristics of the national (health) market and available discourses, as does the navigation through them.

Most studies have been carried out in Western contexts, where the evolution of health markets followed a similar trajectory centered around individual self-management. The connected proliferation of health-related products and services has been well documented (e.g. Gidens, 1991 for a closer analysis). The Central European context, however, has gone through a radically different development in terms of health management and it is only recently that individual responsibility for one's own health began to be stressed. As a result, the consumers' relationship with their own bodies is different than in the West, altering also their relationship with health-related consumption and the market. This should be of particular interest to businesses operating on this market, as efficient marketing should draw on a thorough knowledge of consumers' needs, meanings and practices (Kotler, 2011).

In this paper we set out to explore this interrelationship of a specific cultural setting and the way consumers perceive and construct their bodies. We do so by examining two data sets that build on two separate qualitative studies of consumers' perceptions and practices in the area of health and food in Denmark and the Czech Republic. These two studies were carried out independently on each other, but deal with the same issues. The analysis presented here was a result of the two authors' continuous discussion of the similarities and differences of the perceptions and processes found in the two data sets. Particularly, we explore how consumers deal with body and food consumption through different forms of governmentality mediated by consumer culture. We show that although the notion of the body in consumer culture is often assumed as homogeneous and uniform, as is the working of neoliberal governmentality, we show that the actual experience of consumers' bodies depends on the specific cultural context, thus influencing the way consumers relate to health-related markets.

\section{Body and Consumer Culture}

In consumer culture, body becomes indicative of the success of a consumer's life project, strengthening the view that the body mirrors the moral qualities of a person (Thompson and Hirschman, 1995). This view is not new and has its roots in religious asceticism that also plays a prominent role in the first medical theories based on restraint in bodily pleasures (Turner, 2008). Yet, the prominence of consumption in today's consumer culture underlines the paradox of the way body is constructed. The notion of body today stems from the intersection of two conflicting discourses. On the one hand, consumers are tempted to indulge in all the bodily pleasures the market offers; on the other hand, they are being offered body ideals of healthiness and slimness and are invited to engage in the offered practices of body management (Featherstone, 1982; Lupton, 2005).

Consumers' desire to control their bodies and construct them in a desirable way goes hand in hand with nation states' imperative to do the same, not least because of their need to manage health-related costs. This association has facilitated the control nation states in 
general and medical professions in particular exert over their citizens' bodies in modernity (Shilling, 2003, p. 2). The concept that best describes the process of conjoint control of governments and individuals over their bodies is governmentality referred to as the way in which people are taught to govern themselves. It shapes the way conduct is formed and thus becomes a part of an embodied experience (Foucault, 1977). Governmentality is associated with a neoliberal sense of self, where the solution to a given health problem is considered a personal and individual matter, which calls for a heightened awareness, self-monitoring and responsibility.

While scholars have treated governmentality as an embodied experience (Thompson and Hirschman, 1995; Thompson, 2004; 2005), what has not been sufficiently addressed is the interrelationship between the national cultural context and consumers' experiences of their bodies. While there are certain similarities of late modern experiences of one's own body due to the common heritage of Western thought, the particular discourses concerning bodies differ within particular cultures, not least because of a diverging historical development. These issues dramatically shape consumers' experiences which become heterogeneous across different cultural settings.

Some literature concentrates on the interrelationship of macro-level structures and consumers' life world (Thompson and Hirschman, 1995; Thompson, 2004), yet fails to address the concrete embodied effect of consumer cultures in different cultural contexts. Halkier et al. (2007) concentrate on the macro structures and analyze the discursive framings of food consumers in four national settings. They state that the substantial meaning of a phenomenon - for example, consumer responsibility for food safety - is in principle open and flexible. The production of meaning, however, is far from situational and takes place in relation to a generalized repertoire of meanings in society (Halkier et al., 2007, p. 382). In a similar vein, Berg et al. (2005) analyzed the institutional conditions in four different settings in connection with consumers' trust in food safety. On the other end of the spectrum, the work of Lotte Holms and Helle Kildevang (1996) deals with everyday body-related considerations, yet does not take into account their embeddedness in macro-level structures.

While the body-related macro structures, as well as the phenomenology of bodily experiences have thus been explored, what is lacking in many of these studies is an empirical analysis of how the link between body and society is experienced and lived in concrete settings. How are specific national state systems, histories, values and institutions translated into everyday experience and consumption? Our work takes a point of departure in a comparison of two cultural settings and explores how these are reflected in consumers' everyday perceptions and practices. It leans mostly upon the work of Craig Thompson $(2004,2011)$. Thompson addresses the interrelationships that exist among everyday consumption practices and ideological structures (2011). In his studies of the natural health marketplace, he explores the relationship between specific market structures and cultural myths (2004). Our approach, however, is differentiated from previous studies as it questions the effect of consumer culture as uniform and explores its manifestations in different cultural settings.

\section{Context}

Our context allows to uncover the workings of culture-specific discourses on the level of lived consumption experience. Within a culture such experiences become naturalized and taken for granted, but a cross-cultural comparison allows them to stand out. The 
Czech context presents very different characteristics from Denmark's, which could be considered an advanced consumer culture. This is relevant both from the point of view of consumers, since Danish consumers have been born into consumer culture, and from the point of view of the marketplace, as the Danish market has had time to naturally evolve and create space for a plurality of health and body related discourses that may at times be contradictory, but still share a certain amount of legitimacy. Also, in agreement with ideology of neoliberal governmentality, the state has been very present in health and body related discussions, strengthening the discourse of individual responsibility and offering guidelines of proper behavior that should then be internalized.

\section{Denmark: Health Consumers between Welfare and Privatization}

In Denmark, the health care system has undergone radical changes during the last decade. These changes involve privatization of the health sector in the form of rapid expansion of private hospitals and health services, and the introduction of private health insurance. Also patients' rights and duties are increasingly addressed and politicized, thus securing the active engagement of citizens in the welfare system. As a consequence, new actors providing health insurance, products, and services have emerged. This development has reconfigured the role of the citizens in relation to their own health and the health care system. Rather than being passive patients and recipients of health care prevention, they are increasingly perceived as active health seeking expert patients and consumers with emphasis on autonomy, self-management and responsibility.

The Danish health program stresses the importance of individual behavior, personal responsibility and autonomy by addressing lifestyles and risk factors associated with certain forms of behavior (Vallgårda 2007: 208). Key areas in current health promotion include: tobacco, alcohol, diet and exercise. The public authorities have the obligation to inform the population about risky and unhealthy behaviors as well as to deliver messages and provide solutions (Vallgårda, 2001: 390). Thus, in the public health discourse in Denmark unhealthy behavior is primarily regarded as the major cause of disease and behavior that is dependent on the individuals' free choice. Therefore, the individual is assumed to be responsible for his/her health condition (Ibid). In a Danish white paper, it is phrased in the following way: "Individuals are responsible for their own lives. Everyone has the right to live their lives as they wish: to make their own choices". "Respecting individual autonomy is decisive. The public sector should not control our lives" (cited in Vallgårda, 2007a: 208). The health improvement strategy is to help citizens make their own informed choices. As a consequence, poor health is overall depicted as the result of individuals' inappropriate behavior (Vallgårda 2007b: 45).

\section{Czech Republic: The Legacy of Communism}

Czech Republic presents a rather young consumer culture, with a liberal market that began its evolution a little more than two decades ago. For over forty years, the country was under communist rule. It can be said that during this time, the state was omnipresent in all public life. As a result of abolishing private property, almost everybody became a public employee, making the division between the private and public spheres of life very acute. The public sphere of life, often referred to as "them" was where people felt dominated and manipulated, while the private sphere was where they felt free and secure (Holy, 2010). 
The health system was an integral part of this setting, reflecting the state ideology as well as the overall social climate. From 1951, the system of health insurance was replaced by the direct provision of health care (including medication) by the state through the national budget. Patients were assigned to medical doctors based on their place of residence; alternatively, they were treated in factory-based clinics. Changing doctors was not allowed. The law that sanctioned these changes stated that "Public administration organs and the workers in preventive and curative health care facilities are obliged to continuously increase people's level of health [...], being aware of the importance of health care for a constant advancement of labour force" ( $\$ 3,103 / 1951 \mathrm{Sb}$.). On the other hand, the public administration was allowed to carry out any action needed to ensure health care, such as order preventive check-ups, order treatments, etc. It is not hard to see how, in this setting, health became externalized into the public sphere. Given its total separation from the private sphere, the responsibility for one's own body and health was not a private concern.

After the revolution in 1989, as the economic system moved towards becoming a market economy, the national health care system changed to a degree. Health care is now paid from obligatory health insurance, although there is also a possibility of direct payment. Since public spending on health care outreaches the income from insurance payments, attempts have been made at responsibilizing the population about health care consumption, for instance by introducing so-called "regulatory fees" for each doctor visit of CZK 30 (around EUR 1.2), while discussions about submitting health care to rules of the market multiply. Yet not many actions have been undertaken in the realm of preventive education of consumers, and health communication on the state level is practically nonexistent. The dominant and only legitimate discourse within the health care realm is medical/scientific. The market of alternative health care (outlawed before 1989 ) is very small and it bears the heritage of its former illegitimacy.

\section{Method}

The analysis presented here is based on two separate distinct studies, which, however, share their focus. Both studies have been carried out in the context of food consumption. Food is known to be a highly symbolic area of consumption, especially for the perception of one's own body, and in both studies it thus served as a lens through which to study consumers' experience of their bodies and their sense of agency. The Danish research project was based on the method of participant observation, including shopping trips with 26 consumers (17 women, 9 men) between 20 and 60 years of age, completed with long ethnographic interviews. The informants were recruited in different types of supermarkets, ranging from discount type markets to markets specializing in organic produce. Half of the interviews were conducted in Odense, a major provincial city, and half in Copenhagen, the capital. After the shopping session, interviews were carried out in the informants' homes focusing on food culture, eating behavior and life style. Later, a follow-up interview focused on health and brand symbolism was conducted with the purpose stimulating the informants to reflect more specifically on brands and products.

The Czech part of the project is based on data from 25 introspective essays by young Czech consumers between 20 and 23 years and two in-depth interviews based on visual elicitation with respondents aged 45 (Eva and Vilma). In the introspective essays, 
consumers were asked to write five pages on the topic "Food in my life". This method allowed for a deeper self-reflexivity of the respondents who, through the description of their everyday routine activities, point to their experience of their bodies. The two in-depth interviews were based on collages the informants were asked to bring to the interview that represented how they perceived their body. Again, the visual elicitation allowed for a deeper introspection and self-reflexivity of the respondents on a topic that is not easily grasped and communicated.

\section{Findings}

The data reflects some of the discussions presented above. First of all, the prominent common topic that ran across the data was body as a sign of morality. In both contexts, we found the reflection of body (outer self) as being indicative of the moral value of the consumers' inner self. Such evaluation stems from the notion that body is a plastic and workable entity, one that should be molded and shaped through the use of commodities (Slater, 1997). Secondly, we explore how the notion of agency and self-management is discursively imagined and articulated in the interface between individual and society.

Finally, guiding self-management practices are the underlying beliefs that stem directly from the social organization of the health industry in the two national contexts. Here we found that food consumption is closely associated to notions of trust and mistrust (Luhmann, 1979) and is illustrative of the competing strategies of modern governance of health that shape the discursive environment which consumers struggle to navigate.

\section{The Body as a Sign of Morality: The Danish Context}

The shopping basket is a window from which we get information about moral issues and consumer choices, but also of the norms and constraints that shape consumers' choice. In this way, the items in the shopping baskets become signs of the moral character of the shopper.

I really believe that you can get very far by eating healthy and living healthy in relation to your look. I like watching when people are shopping. When I stand in a line in the supermarket, I like observing people's purchases. I simply love staring into people's shopping basket, just stand there being really judgmental (laughs).

Interviewer: And in which way are you judgmental?

Well, it is all about the white toast, and those kinds of things, eggs from battery hens, all those things that I have left behind. And then the fat meat. Well look at that. Then no wonder they are so fat. So I really become judgmental, if they have bought 3 liters of cola, then please, stop it. Lots of candy. No vegetables (laughs).

What we see here is an example of what Thompson and Hirschman (1995) refer to as "the disciplinary gaze": the socialized moral values that are behind the association between the items of the shopping basket, bodily shape and moral character. Consequently, in the Danish context, health is strongly associated with the notion of lifestyle and a slim figure. The bodily shape is regarded as a reflection of the person's capability to control food consumption and lead a healthy life. This resonates with the Christian notion of morality, according to which a moral person should be able to control his/her bodily desires. 
In the Danish context, we also find a discursive emphasis on "normality", a concern for living a "good life", which is perceived as contrary to allegedly "extreme" principles of healthy eating. The aim is to keep a balance between indulgence and principles of healthy eating (Warde, 1997). This reflects a view of the body that is subjected to the will of its owner. It is, however, very important not to go to extremes, and to find the balance between control and indulgence.

If people become too holy, that is too extreme. Then it seems as though they never relax. I would never go to that extreme with my own body as not allowing myself to go for a beer. That kind of people annoy me, because there needs to be space also for the forbidden, as drinking good beer and eat good food without the minimal fat content. (Anders)

It is a key point to find the right balance and not go to extremes, so it is all about finding your personal equilibrium between pleasure and discipline, within the norms of society.

\section{Czech Context}

Similarly to what is seen in the Danish context, within the Czech culture, health and body are regarded as pivotal moral values. There is a clear movement towards seeing the body as a part of a project, an entity to work on, while there is a strong interconnection between healthy diet, bodily appearance and health. What can be detected is also the Christian notion of morality that requires resisting temptations of the flesh. The "disciplinary gaze" (Thompson and Hirschman 1995) and the link between one's shopping basket, bodily appearance and moral value is explicated by Eva.

Sometimes you even see a whole fat family or a couple, man and woman, both are like 110 kilos or something like that and their shopping cart is bursting, there is coke there, chips. I don't buy these things at all. [...] Well, and when I see sometimes a totally fat person having an overflowing shopping cart, well those people can't care, they must know that they are fat for this reason, I hope they wouldn't want to say they eat little and are fat and that they are ill or something, that it's not because of the food, but moreover I think a lot of people don't know what they should eat, and they don't care... (Eva)

Interestingly, the Czech data do not present any judgement based on other moral issues central to identity-construction of consumers, such as socially responsible consumption. In the Danish context, the morality of a person also seems to be connected to politically active consumption (such as eggs from battery hens). It could be argued that politically active consumption is one of the issues that emerge later on in a society acculturating to consumer culture.

What clearly emerges from the quote is the perceived self-responsibility to "construct" the body. While trying to do so, one must control the temptations of the flesh and the most immoral temptations are those that come as an emblem of consumerism. Although traditional Czech food is not considered as healthy, it is a person who gives in to the market temptations that is seen as immoral. This is vividly pictured by Jakub, who describes a McDonald's eater as an immorally fat man. A person who eats traditional Czech food is merely disadvantaged, as s/he "needs" this kind of food every day. 
I want to "die healthy", so I try to eat that way. In this regard, I have a pretty big advantage, because I don't need too fatty and unhealthy meals. I don't like all kinds of sausages and salamis, and I do not need sirloin [a traditional Czech creamy sauce eaten with sirloin] or other similar sauce every day. I don't seek fried foods, foods in which stuff swims submerged in fat. I don't go to fast-food places such as McDonald's or KFC, and yet I don't feel impoverished, unlike many of my peers, who cannot imagine not going to these places at least once a week. When I hear the word McDonald's, I see a classic fat-man with a minimum of three fatty tires with oil running down his face wiping his oily fingers into his T-shirt, because he cannot even bend for a napkin. (Jakub)

Similarly as in the Danish context, what can be noticed is a search for a certain balance and normality. Living too healthy is seen as a stigma, as one who buys too much into the "healthy living" is also giving in to consumerism and its dictates. Healthy food, moreover, is viewed as something connected to dieting in the narrow sense of weight reduction. However, the balance here is much more closely connected to a mechanistic view of the body as a machine that needs a balanced amount and kind of fuel in order to function properly.

You would think from what I wrote in the beginning that I don't eat anything else than some vegetable salads and super diet foods without any taste, but it is not true. I just don't like the feeling in my stomach that follows greasy and heavy food. That's why I prefer pasta that is light and I can eat loads of it. It also contains carbohydrates, so it's good to be eaten before a sports performance, because they give the body the necessary energy. (Jakub)

\section{Danish Context: Self-management by Listening to Own Inner Voice}

With the imperative to construct one's body comes the question of how this should be done. In the Danish context, healthy living is considered a question of personal responsibility and is a matter of personal and individual choice. Thus, in order to navigate in the arena of consumption, the individual body becomes a mechanism that can be used as a guiding principle. By relying on the "inner voice" and "gut feeling" which is perceived as a signal to the owner, the consumer decides whether a certain food product is right or wrong (Lupton, 1996). As a consequence, healthy living implies a critical attitude towards the food you eat, and the capability of making judgment in categorizing food in what is good and bad for you based on the inner feeling.

Listening to one's inner voice is rather complicated, as different voices may rise that do not necessarily imply guidance to a healthy lifestyle. On the one hand, there is a voice that is an expression of a real need, as a call from nature, free of the pollution and interference of modern society. On the other hand, we have the voice that "craves" the forbidden foods. Consequently, the goal for a consumer is to connect with the voice that reveals the "true" needs. As one informant phrased it: "Ideally people do not need advertisement to find out what to put in their shopping baskets. The horse knows that grass is good. We should also feel inside ourselves what is good for us". In contrast, if you give in to the "cravings", this reflects the loss of control and contact with the "inner self" and is considered a "sign" that you are "enslaved" by your own moral weakness. 
Cola makes you fat and unhealthy. You do not see fat people on the street without a cola in their hand. They always come strolling down the streets with this $1 / 2$ liter bottle of cola in their hand...people seem addicted to that stuff...and again, those fat people, I cannot stand the thought of it...drinking cola is one of the great sins for the real overweight.

Thus addiction may be seen as a manifestation of inner struggle, where one part of the person desires sugar/food, leading into temptation and sin, while the other voice, the "authentic" and "healthy" self shows the way to healthy living.

\section{Czech Context: Self-management by External Imposition/Metric- Scientific Approach}

Although self-management is a key concept found in the Czech data as well, consumers do not rely on their inner voice. The bodily perceptions are not trusted, as the body is perceived in a rather mechanistic way. As a result, even in cases when the perception of an inner voice appears, it needs to be explained in a sufficiently mechanistic and popularscientific way.

Apart from the lost kilos, another positive thing was the overall better feeling during the day. While after a fatty and heavy lunch, due to the unbalanced sugar levels one is falling asleep, after a light and balanced lunch I was able to continue working normally. (Lara)

What emerges are the mechanical processes within the body (described in scientific terms as unbalanced sugar levels) rather than the "inner self" that indicates what should be eaten or not. This approach appears also in the description of the bodily desires that in the Danish context stand out as a lack of connection with the "inner voice" that guides towards healthy living. Here, the craving of the body emerges again as a consequence of mechanical processes within the body, such as unbalanced sugar levels.

If the dinner wasn't quite enough, a second dinner follows, but it is not so frequent. It's more about having a sweet tooth, so I'm looking for something that would satisfy my craving, either sweets or something salty. Usually it ends with me having chocolate. Then I must level out the sugar level and craving for something salty follows, mostly in the form of chips of various flavors and similar. (Johana)

What is evident from the above is the dismissal of the inner voice as a guiding principle for one's bodily conduct. What follows is the need of other, external guidelines and forces that will provide guidance for navigating the market. These are represented by the dominant medical discourse and are internalized on an individual level through practices of body control.

I look forward to weighing myself. Well, I look forward to seeing I weigh the same. But I can already tell quite a lot from the food... according to what I ate that day and how much exercise did I have. I know for example that sometimes during the weekend, when I have to work and don't have so much exercise, I don't even go out for a walk [...], sometimes I eat something, I just crave something or I'm out and eat more than I should, then I feel it that the following day I will weigh a little more. (Eva) 
The practices of bodily control can lead towards the inner self being a guiding principle, yet it is still within a framework of external and mechanistic imposition of control.

\section{DK: Mistrust towards External Forces but within the Security of the State}

In the case of Denmark we found many examples of consumers that rely on their common sense and gut feeling as reflecting an "inner core" as the main guiding principle. They trust persons and sources of information that somehow resonate with this "inner core", which can be considered a form of almost extreme subjectivization, as the subjective feelings stand as the ultimate testing device of reality. This leads to skepticism towards the traditional hierarchies of knowledge in society, in this case health authorities and health professionals. One way to state one's "inner core" is by marking distance to commercial and marketers, who are believed to tempt people to buy products that are only claimed to be healthy for them. As one woman commented when presented with a small yogurt containing a special healthy bacteria from the dairy company Arla "I believe it is marketed as an easy solution to get a healthy life, like this 'take this and you will be healthy the rest of your life'. The thing is, I simply do not believe in it". In this way the healthy life is regarded as something you can acquire if you steer free of the temptation of the market, and the seduction of commercials and marketers, and instead seek "pure" and "natural" products, from companies with a higher ethical awareness and standard, as one says:

The thing is that I would never consider buying any of these products. If I want something healthy, I rather go directly to the source instead of buying something that has been through so many processes and then mixed into a sort of product.

It is interesting here to note, however, that the state provides a guarantee for a safe consumer choice in the form of regulation for food safety and quality. As one woman remarks:

I really like that there are some guidelines from the food authorities, and I really like that we are more strict than others, that is really nice. That makes it possible for me to take the decisions I take. Because I think a bit that it cannot go that wrong, as long as there is some control and surveillance.

Accordingly, consumer choices can unfold in their purest form, as the possible risk is minimized

\section{Czech Context: Mistrust towards One's Body}

In the Czech context, the knowledge hierarchy presents a different structure. There is no strong official state-originated discourse on healthy living/eating. Health discourse is thus composed of a kaleidoscope of popular-cultural information (internet sources, newspapers, magazines, TV programs) that originates on a background of medical and scientific hegemony. Even when respondents perceive a multiplicity of discourses, the external authority that provides it is not questioned, as is the case in the Danish context. 
What is, however, questioned, is the trustworthiness of own body. It has been already noted how Czech respondents do not rely on their inner voice without a satisfying explanation. This need for explaining one's bodily perceptions may stem from this essential mistrust. Body (rather than external forces) is presented as an enemy that needs to be constantly controlled (with the help of external forces). This was reported by Vilma, who sees obesity as a victory of the body-enemy. The bodily perception is seen as mostly deceptive. Here it is "feeling good" when overeating, but this inner voice of the body should not be listened to, if one does not want to become enslaved by it (through heavy food addiction).

When somebody is fat, I think it is just a heavy food addiction. [...] We use food as a stimulus, because we feel good in it. You eat and say "Wow, that's great", she had two cakes and "Wow, I don't care about anything now, let everyone do what they want with me". But of course, if you drink or smoke, there's consequence. With food it's the kilos [...], but the system is the same. (Vilma)

Because the inner voice that stems from the body cannot be truly trusted, there is a need for a trusted external help. Most prominently, because of the hegemony of medical/ scientific knowledge, medical doctors are seen as the experts, who can guide consumers to control their undisciplined bodies.

I used to have a wonderful doctor, but she got sick [...] And when I disappeared from her sight, I just... without the control... I just feel comfortable, when I have someone controlling me beside or above me. A person that will tell me 'look, be careful about this.' I know it, but if I have someone to consult it with, I feel stupid to [not follow the rules]. If I'm alone with myself, I say 'well, yeah, so what, I will start doing it when it's warm, I will walk...' and well, half a year goes by and other two kilos appear there and then you find out you have 8 more kilos and that's terribly hard to start [...]. It's about finding a good therapist. It's like with psychiatry, [...] these nutritionists who treat obese people are a sort of psychologists [...] so when I have this partner that pulls me somewhere, now it is this other doctor who helps me lose weight, that's a stimulus for me. (Vilma)

This trust in authorities, especially in the medical profession, may be due to the absence of the state authority in the realm of consumer safety. The state does not offer a sufficient guarantee of safe consumer choice and the perceived risk of this lack is strengthened by proliferation of popular discourses that revolve around low quality of products in the market and its insufficient control from the state.

\section{Conclusion}

To explore the way the cultural context shapes consumer meanings and practices in the health-related market, we have explored consumers' notions of bodies in relation to health and food consumption as a mediation between subjective experiences and cultural context (Thompson \& Hirchman, 1995; Turner, 2008). We have here pointed out two of the forces that shape consumers' bodily experiences, firstly consumer culture and secondly the cultural context. We have explored how the national cultural context with its specifics reflects in the microphysics of consumers' bodily experiences and health choices. We 
have done so by pointing to the notion of trust and mistrust as a tool that consumers use to navigate safely within the risky arena of health-related marketplace. This (mis)trust leads towards different modalities of self-government, which in turn lead to different consumer behavior, meanings and practices. However, this process is not universal and homogeneous, but is dependent on the local context and its historical development. In this way, we can say that governmentality is not universal but contextually defined and can be observed in everyday bodily practices.

In both contexts body is seen as a sign of a person's moral value. This notion stems from the body/mind dualism (Thompson and Hirschman, 1995) that is at the base of the Christian ethos of controlling the bodily desires of the flesh through the mind. As both contexts are built on Christian tradition, this similarity is not surprising. As a consequence, respondents make judgments of fellow consumers based on their health and body-related consumption choices and their bodily shape. Obese bodies are then seen as bodies "out of control" and as belonging to amoral individuals. This view is enforced by the late modern conditions that construct consumers as responsible for the self-reflexively fabricated project of the self (Giddens, 1991). The body is regarded as a reflection of the success of this project. Accordingly, it must be "produced" (with the help of the market) as such.

What differs in the two contextual settings is the modality of production of "successful" bodies that stems from different locus of trust. In the Danish case, the stress on individual autonomy has been communicated by authorities and has been backed by the security the state offers. The Danish state offers a system that ideally guarantees the security of consumer choice. The Danish consumer then feels the freedom to make autonomous choices as the system ensures these cannot be hazardous. The internalization of the neoliberal discourse on the individual level is facilitated by the safety net provided by the social welfare state. Consequently, consumers feel free to rely on their own inner voice and question the traditional health-related knowledge hegemony.

In the Czech context, the society is in transition from a system in which individual health was a public issue and was almost entirely separated from the private lives of consumers. Although health-care was partially privatized, the state discourse is limited to mild discussions of citizens' responsibility for their health. Consumer protection is perceived as scarce, as is official health-related communication. Popular discourse often highlights the low quality of food compared to neighboring countries and high quality of medical profession. The neoliberal self becomes internalized by the Czech consumers. However, with the absence of the safety net consumers need to rely on medical/scientific expert systems that reflect the health-related knowledge hegemony. They cannot rely on their own body's inner voice, as this may prove to be too hazardous.

\section{Managerial and Public Policy Implications}

In this paper, we have explored the ways in which consumers use the marketplace offerings to work on their bodies. The results of our analysis show that the meanings of the various offerings in the health-related market are by no means straightforward and unequivocal. On the contrary, even apparently healthy choices made by consumers can be evaluated negatively as being too obsessive. Depending on the cultural setting, then, consumers use different mechanisms to make the evaluation of whether a particular choice is healthy or not. While in Denmark consumers rely on their inner voice, the 
Czech consumers do not trust this inner voice and prefer the expert voice to tell them what is healthy. They also prefer the metric/scientific language that will explain the benefits of the particular offering. These findings shed light on the way consumers make choices in the marketplace. Thus, they should be taken into consideration when designing the marketing mix in these markets: be it in terms of the product definition (where not every seemingly healthy choice is perceived as healthy and vice versa) or marketing communication, where different sources of information are trusted in different settings.

The health-related market has been steadily growing throughout the developed world and it can be expected that this trend will continue, as the governmental pressure on individuals' responsibility for their own health will increase. However, this growth hides different consumer processes and meanings that should be taken into consideration, if businesses wish to create offers relevant to their consumers.

In terms of public policy, we have shown that the pure neoliberal model of consuming individuals and the least interference from the state actually produces less autonomous consumers who need to rely on dominating expert systems in their consumption choices. In this way, it precludes free competition in a sense as it favors certain parts of the market and not others. Notably in this case, the part of the market it favors is the public health care system that needs to be funded by the state itself. As a result, the new state neoliberal ideology is paradoxically precluded by the lack of market regulation. More intervention from the state in terms of market regulation produces more confident consumers, as they can move more freely in the marketplace, ensuring a better competition in more than a few of its areas. It creates consumers who believe themselves to be autonomous and not in need of dominant expert systems.

\section{References}

Baudrillard, J. (1998). The Consumer Society. London: Sage publications.

Berg, L., Kjaernes, U., Ganskau, E., Minina, V., Voltchkova, L., Halkier, B., \& Holm, L. (2005). Trust in food safety in Russia, Denmark and Norway. European Societies, 7(1), 103-129.

Featherstone, M. (1982). The Body in Consumer Culture. Theory, Culture \& Society, 1(2), 18-33.

Featherstone, M. (1991). Consumer Culture \& Postmodernism. London: Sage publications.

Foucault, M. (1970). The Order of Things. An Archaeology of the Human Sciences. New York: Vintage Books

Foucault, M. (1977). Discipline and Punish. The Birth of the Prison. New York: Random House.

Giddens, A. (1991). Modernity and Self-identity. Stanford: Stanford University Press.

Gershon, I. (2011). Neoliberal Agency. Current Anthropology, 52(4), 537-555.

Halkier, B., \& Holm, L. (2008). Food consumption and political agency: On concerns and practices among Danish Consumers. International Journal of Consumer Studies 32(6), 667-674.

Halkier, B., Holm, L., Domingues, M., Magaudda, P., Nielsen, A., \& Terragni, L. (2007). Trusting, complex, quality conscious or unprotected. Journal of Consumer Culture 7(3), 379-402.

Holm, L., \& Kildevang, H. (1996). Consumers' views on food quality. A qualitative interview study. Appetite, 27(1), 1-14.

Holy, L. (2010). Malý český člověk a skvělý český národ. Praha: Slon.

Rose, N. (1989). Governing the soul: The shaping of the private self. London: Routledge.

Schilling, C. (2003). The Body and Social Theory. London: Sage Publications. 
Slater, D. (1997). Consumer Culture and Modernity. Cambridge: Polity Press.

Thompson, C. J. (2011). Understanding Consumption as a political and moral practice: Introduction to the special Issue. Journal of Consumer Culture, 11(2), 139-143.

Thompson, C. J. (1997). Interpreting Consumers: A hermeneutical framework for Deriving Marketing Insights from the texts of Consumers' Consumption Stories. Journal of Marketing Research, 34(4), 438-455.

Thompson, C. J. (2004). Marketplace Mythology and Discourses of Power. Journal of Consumer Research, 31(1), 162-180.

Thompson, C. J., \& Hirschman, E. C. (1995). Understanding the Socialized Body: A Poststructuralist Analysis of Consumers' Self-Conceptions, Body Images, and Self-Care Practices. Journal of Consumer Research, 22(2), 139-153.

Turner, B. S. (2008). The Body and Society: Explorations in Social Theory. London: Sage.

Vallgårda, S. (2007a). Public health policies: A Scandinavian model? Scandinavian Journal of Public Health, 35(2), 205-211.

Vallgårda, S. (2007b). Health inequalities: Political problematizations in Denmark and Sweden. Critical Public Health, 17(1), 45-56.

Warde, A. (1997). Consumption, Food and Taste: Culinary Antinomies and Commodity Culture. London: Sage.

Weber, M. (1958). Protestant Ethic and the Spirit of Capitalism. New York: Scribner.

\section{Authors}

\section{Zuzana Chytkova}

Assistant Professor

Department of Marketing, Faculty of Business Administration

University of Economics, Prague

Nam. W. Churchilla 4

130 67, Prague 3

Czech Republic

zuzana.chytkova@vse.cz

\section{Dorthe Brogård Kristensen}

Associate Professor

Department of Marketing \& Management, University of Southern Denmark, Odense, Denmark

Marketing \& Management, University of Southern Denmark

Campusvej 55, 5230 Odense M

dbk@sam.sdu.dk 